\title{
LAPTM4B polymorphism is associated with non-small cell lung cancer susceptibility and prognosis
}

\author{
HAN TANG, HUI TIAN, WEIMING YUE, LIN LI, SHUHAI LI, CUN GAO, \\ LIBO SI, LEI QI, MING LU and WENSI HU
}

Department of Thoracic Surgery, Qilu Hospital, Shandong University, Jinan, Shandong 250012, P.R. China

Received January 31, 2014; Accepted March 12, 2014

DOI: $10.3892 / o r .2014 .3116$

\begin{abstract}
Lysosome-associated protein transmembrane- $4 \beta$ (LAPTM4B) is a novel cancer-related gene that is upregulated in many tumors, and which plays important roles in carcinogenesis. It has two alleles, $L A P T M 4 B^{*} 1$ and $L A P T M 4 B^{*} 2$. $L A P T M 4 B^{*} 1$ contains only one copy of a 19 -bp sequence in the first exon, whereas $L A P T M 4 B^{*} 2$ contains two tight tandem segments. Previous studies have shown that $L A P T M 4 B^{*} 2$ is a risk factor for susceptibility and prognosis of many tumors. The present study investigated the relationship between $L A P T M 4 B$ polymorphism and non-small cell lung cancer (NSCLC) susceptibility and prognosis. We identified LAPTM4B genotypes with polymerase chain reaction (PCR) in peripheral blood samples. In the adjusted multivariate logistic regression analysis, we found that $L A P T M 4 B^{*} 1 / 2, L A P T M 4 B^{*} 2 / 2$ exhibited 1.48-fold [95\% confidence interval (CI), 1.076-2.037] and 2.855 -fold (95\%CI, 1.722-4.734) increases in the risk of developing NSCLC compared with non-LAPTM4B*2 carriers. Furthermore, our results showed that overall survival time and disease-free survival time of patients with $L A P T M 4 B^{*} 2$ were significantly shorter than in patients carrying $L A P T M 4 B^{*} 1$ $(\mathrm{P}=0.001$ and $\mathrm{P}=0.001$, respectively). In addition, multivariate Cox regression analysis revealed that $L A P T M 4 B^{*} 2$ was also an independent prognostic factor for NSCLC. These results suggest that $L A P T M 4 B$ polymorphisms may be a prospective marker for evaluating the risk and prognosis of NSCLC.
\end{abstract}

\section{Introduction}

Primary lung cancer is the most commonly diagnosed malignant tumor in the world. It is reported that the number of new lung cancer cases in 2008 was 1.6 million, accounting for $13 \%$ of the total cancer cases. Due to its insidious symptoms, late clinical presentation and rapid progression, there are 1.4 million deaths annually making it the leading cause

Correspondence to: Professor Hui Tian, Department of Thoracic Surgery, Qilu Hospital, Shandong University, 107 Wenhua Xi Road, Jinan, Shandong 250012, P.R. China

E-mail: tianhuiql@sina.com

Key words: lysosome-associated protein transmembrane-4 $\beta$, gene polymorphism, susceptibility, prognosis, non-small cell lung cancer of cancer-related mortality worldwide (1). Non-small cell lung cancer (NSCLC) accounts for $\sim 75-80 \%$ of cases (2). It is widely accepted that genetic heterogeneity and environmental factors result in the onset of lung cancer simultaneously. Smoking is the most well-established cause of lung cancer, yet non-smokers take up a very large proportion of lung cancer patients, suggesting the genetic variants also play a role (3-5). It is of utmost importance to identify novel molecules for the detection and diagnosis of lung cancer.

Lysosomal-associated protein transmembrane- $4 \beta$ (LAPTM4B), a novel oncogene candidate, was initially identified in hepatocellular carcinoma. It is cloned using fluorescence differential display, rapid amplification of cDNA ends and reverse transcription-polymerase chain reaction (RT-PCR). According to BLAST program analysis, it is located in chromosomes $8 \mathrm{q} 22$ and is composed of seven exons separated by six introns $(6,7)$. It was previously reported that $L A P T M 4 B$ protein was markedly overexpressed in various malignant tumors, including pancreatic (8), gallbladder (9), ovarian (10) and cervical cancer (11). Two alleles of the $L A P T M 4 B$ gene have been recognized, designated as $L A P T M 4 B^{*} 1$ and LAPTM4B*2 (GenBank nos. AY219176 and AY219177, respectively). The difference between $L A P T M 4 B * 1$ and $L A P T M 4 B * 2$ is the sequence at the $5^{\prime}$ untranslated region (UTR) in the first exon. As shown in Fig. 1, LAPTM4B*1 contains only one copy of a 19-bp sequence whereas $L A P T M 4 B^{*} 2$ contains two tight tandem segments.

Previous studies showed that there was an association between $L A P T M 4 B$ polymorphism and increased risk of hepatocellular carcinoma (12), gastric cancer (13), colorectal cancer (14), gallbladder (15) and ovarian carcinoma (16), and breast cancer (17). Two laboratories studied the relationship between LAPTM4B polymorphism and susceptibility of lung cancer, however, they drew completely different conclusions $(18,19)$; one reported that $L A P T M 4 B^{*} 2$ was associated with NSCLC susceptibility, but the other found no relationship. Less than 200 patients were included in each group, therefore, their conclusions are not very conclusive. Meanwhile, the two groups included all types of histological lung cancer in the samples. It is known that the development of small cell lung cancer and NSCLC has a considerable difference, and $L A P T M 4 B$ polymorphism might influence only a certain histological type, thus it is less rigorous not to divide them. Hence, it is necessary to enrol more patients to rigorously 


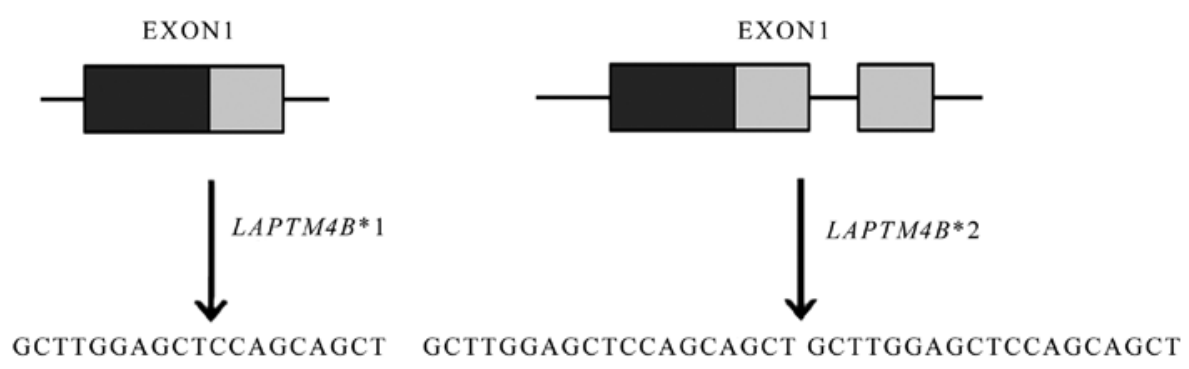

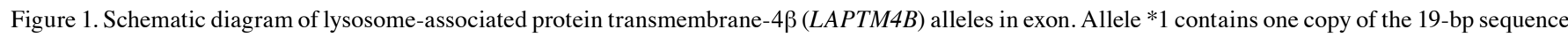
segment (gray box), while allele $* 2$ contains two tight tandem 19-bp sequence segments. The lower panels display the DNA sequence in the gray boxes.

and deeply explore whether there is a relationship between $L A P T M 4 B$ polymorphism and risk of NSCLC. In addition, $L A P T M 4 B^{*} 2$ is also a marker of poor prognosis in gallbladder (20) and hepatocellular carcinoma (21), breast (17) and endometrial cancer (22), while its function in the prognosis of lung cancer patients has not been clarified. The present study was designed to study the effects of LAPTM $4 B$ gene variants on the susceptibility of NSCLC via a large sample size. Furthermore, the relationship between $L A P T M 4 B$ genotype and prognosis of NSCLC was also analyzed.

\section{Materials and methods}

Patients and controls. A total of 392 blood samples of patients were collected from Qilu Hospital of Shandong University between July 2007 and October 2010. All patients underwent surgical resection and were diagnosed as NSCLC by at least two pathologists. For all patients, histological type of lung cancer was determined by the World Health Organization classifications, and pathological staging was based on the international staging system revised in 2009 (23). Also, 437 cancer-free individuals attending the physical examination in Qilu Hospital of Shandong University were recruited as controls. All blood samples were stored at $-80^{\circ} \mathrm{C}$ for further studies. To analyze the association between NSCLC patients prognosis and $L A P T M 4 B$ polymorphism, we performed a retrospective study. September 30, 2013 was the end date of follow-up, therefore, a total of 101 cases diagnosed as NSCLC before September 31, 2008 were investigated and analyzed. Of these 101 patients, 4 were excluded ( 3 patients were lost to follow-up, 1 patient died of perioperative complications), thus, 97-long-term follow-up patients were enrolled in this retrospective study. Each patient signed an informed consent according to the Helsinki Declaration and the present study was approved by the Ethics Committee of Qilu Hospital.

DNA extraction. Genomic DNA was extracted from a $1 \mathrm{ml}$ peripheral blood sample obtained from each participant using a RelaxGene Blood DNA System (Tiangen, China) according to the protocol provided by manufacturer. Then, the newly extracted genomic DNA was stored at $-20^{\circ} \mathrm{C}$ for the subsequent PCR analysis.

DNA genotyping. Polymorphism of LAPTM4B was determined by PCR analysis using the specific primers. The primer sequences were: forward, 5'-GCCGACTAGGGGACTGGC GGA-3' and reverse, 5'-CGAGAGCTCCGAGCTTCTGCC-3'

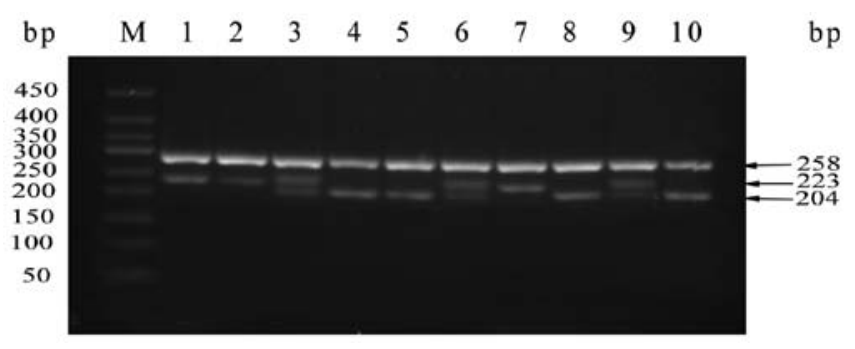

Figure 2. Genotyping of LAPTM4B. Samples were analyzed by separation in $2.5 \%$ agarose gel electrophoresis. Lane M, DNA marker $(50,100,150$, 200, 250, 300, 350, 400 and $450 \mathrm{bp}$ ). The lower bands represent the target products. Lanes 4, 5, 8 and 10: genotype $* 1 / 1$; lanes 1, 2 and 7: genotype $* 2 / 2$; lanes 3,6 and 9: genotype $* 1 / 2$. The upper bands show the amplified product of human GAPDH $(258 \mathrm{bp})$ that served as the positive internal control. LAPTM4B, lysosome-associated protein transmembrane- $4 \beta$.

(7). The PCR was conducted under the standard procedure in a $20 \mu \mathrm{l}$ reaction mixture, which included $10 \mu \mathrm{l}$ 2XPCR mix (TransGen, China), $1 \mu \mathrm{l}$ sense primer, $1 \mu 1$ reverse primer, $2 \mu 1$ template DNA and $6 \mu 1 \mathrm{ddH}_{2} \mathrm{O}$. The PCR conditions were: predenaturation at $95^{\circ} \mathrm{C}$ for $5 \mathrm{~min}, 35$ cycles of denaturation at $94^{\circ} \mathrm{C}$ for $30 \mathrm{sec}$, annealing at $68^{\circ} \mathrm{C}$ for $30 \mathrm{sec}$, extension at $72^{\circ} \mathrm{C}$ for $30 \mathrm{sec}$, then final extension at $72^{\circ} \mathrm{C}$ for $5 \mathrm{~min}$. Human glyceraldehyde-3-phosphate dehydrogenase (GAPDH) was regarded as the positive inner control, which was a 258-bp fragment. The primer sequences were: sense, 5'-TGTCG CTGTTGAAGTCAGAGGAGA-3' and reverse, 5'-AGAACA TCATCCCTGCCTCTACTG-3'. PCR products were analyzed by electrophoresis in a $2.5 \%$ agarose gel and visualized with ethidium bromide.

Statistical analysis. Statistical analyses were performed using SPSS 18.0 software (SPSS, Inc., Chicago, IL, USA). The Chi-squared test or the Fisher's exact was used to test the genotypic frequencies of the patients and controls for HardyWeinberg equilibrium and to examine the association between $L A P T M 4 B$ genotype and the patient clinicopathological factors. The relationship between $L A P T M 4 B$ polymorphisms and susceptibility to NSCLC was estimated using unconditional logistic regression method. The Kaplan-Meier method and log-rank test were used to calculate survival curve and to compare the statistical significance of survival differences among patient subgroups. Multivariate Cox regression analysis was carried out to identify the potential prognostic factor of NSCLC patients. P-value $<0.05$ was considered to indicate a statistically significant difference. 
Table I. Distribution of gender and age in case and control groups.

\begin{tabular}{lccc}
\hline & $\begin{array}{c}\text { Controls } \\
(\mathrm{n}=437) \\
(\%)\end{array}$ & $\begin{array}{c}\text { Cases } \\
(\mathrm{n}=392) \\
(\%)\end{array}$ & $\mathrm{P}^{\mathrm{a}}$ \\
\hline $\begin{array}{l}\text { Gender, n (\%) } \\
\text { Male }\end{array}$ & $257(58.8)$ & $212(54.1)$ & \\
Female & $180(41.2)$ & $180(45.9)$ & \\
$\begin{array}{l}\text { Age, years, } \mathrm{n}(\%) \\
\quad<60\end{array}$ & $253(57.9)$ & $158(40.3)$ & $\mathbf{P}<\mathbf{0 . 0 0 1}$ \\
$\geq 60$ & $184(42.1)$ & $234(59.7)$ & \\
& & &
\end{tabular}

a Analysis by Chi-square test. Bold number indicates a statistically significant difference in this analysis.

Table II. Distribution of genotypes and alleles of LAPTM4B in case and control groups.

\begin{tabular}{lccr}
\hline & $\begin{array}{c}\text { Controls } \\
\mathrm{n}(\%)\end{array}$ & $\begin{array}{c}\text { Cases } \\
\mathrm{n}(\%)\end{array}$ & OR $(95 \% \mathrm{CI})^{\mathrm{a}}$ \\
\hline Genotypes & & & \\
$* 1 / 1$ & $226(51.7)$ & $158(40.3)$ & \\
$* 1 / 2$ & $176(40.3)$ & $171(43.6)$ & $\mathbf{1 . 4 8}(\mathbf{1 . 0 7 6 - 2 . 0 3 7})$ \\
$* 2 / 2$ & $35(8)$ & $63(16.1)$ & $\mathbf{2 . 8 5 5}(\mathbf{1 . 7 2 2}-\mathbf{4 . 7 3 4})$ \\
Total & $437(100)$ & $392(100)$ & \\
Alleles & & & \\
$* 1$ & $628(71.9)$ & $487(62.1)$ & \\
$* 2$ & $246(28.1)$ & $297(37.9)$ & $\mathbf{1 . 6 4 9}(\mathbf{1 . 3 1 6 - 2 . 0 6 8})$ \\
Total & $874(100)$ & $874(100)$ & \\
\hline
\end{tabular}

aData were calculated by logistic regression analysis and adjusted for age status. OR, odds ratio; CI, confidence interval. LAPTM4B, lysosome-associated protein transmembrane- $4 \beta$. Bold numbers indicate statistically significant differences in this analysis.

\section{Results}

LAPTM $4 B$ genotypes. Three different LAPTM $4 B$ genotypes designated $L A P T M 4 B^{*} 1 / 1, L A P T M 4 B^{*} 2 / 2$ and $L A P T M 4 B^{*} 1 / 2$ were identified by PCR-agarose gel electrophoresis analysis. As shown in Fig. 2, 10 representative individuals were chosen to display the polymorphism of LAPTM4B genotypes. LAPTM4B*1/1 displayed a 204-bp fragment, LAPTM4B*2/2 displayed a 223-bp fragment and LAPTM4B*1/2 had both fragments. The upper 258-bp band in each lane in Fig. 2 was $G A P D H$ as the positive inner control.

LAPTM4B polymorphism and NSCLC susceptibility. We collected 392 NSCLC subjects and 437 cancer-free control subjects for the present study. The main characteristics of the patients and controls are presented in Table I. The mean age of cases and controls was 58.8 and 55.4 years, respectively. We divided the ages into two groups on the basis of the median age. There was no statistical significance in gender between cases
Table III. Distribution of three genotypes of LAPTM4B in relation to clinicopathological variables in 392 patients with non-small cell lung cancer.

\begin{tabular}{|c|c|c|c|c|c|c|}
\hline \multirow[b]{2}{*}{ Variables } & \multirow{2}{*}{$\begin{array}{l}\text { No. of } \\
\text { cases }\end{array}$} & \multicolumn{3}{|c|}{$\begin{array}{l}\text { LAPTM4B } \\
\text { genotypes }\end{array}$} & \multirow[b]{2}{*}{$\chi^{2}$} & \multirow[b]{2}{*}{$\mathrm{P}^{\mathrm{a}}$} \\
\hline & & $* 1 / 1$ & $* 1 / 2$ & $* 2 / 2$ & & \\
\hline Gender & & & & & 1.907 & 0.358 \\
\hline Male & 212 & 82 & 91 & 39 & & \\
\hline Female & 180 & 76 & 80 & 24 & & \\
\hline Age (years) & & & & & 0.048 & 0.976 \\
\hline$<60$ & 158 & 64 & 68 & 26 & & \\
\hline$\geq 60$ & 234 & 94 & 103 & 37 & & \\
\hline Pathological type & & & & & 0.741 & 0.69 \\
\hline $\mathrm{AC}$ & 220 & 85 & 100 & 35 & & \\
\hline $\mathrm{SCC}$ & 172 & 73 & 71 & 28 & & \\
\hline Differentiation & & & & & 12.924 & 0.012 \\
\hline Well & 109 & 56 & 40 & 13 & & \\
\hline Moderately & 129 & 54 & 58 & 17 & & \\
\hline Poorly & 154 & 48 & 73 & 33 & & \\
\hline Tumor size $(\mathrm{cm})$ & & & & & 0.622 & 0.733 \\
\hline$<4$ & 200 & 77 & 89 & 34 & & \\
\hline$\geq 4$ & 192 & 81 & 82 & 29 & & \\
\hline
\end{tabular}

Lymph node

$3.003 \quad 0.223$ metastasis

$\begin{array}{lllll}\text { No } & 186 & 83 & 77 & 26 \\ \text { Yes } & 206 & 75 & 94 & 37\end{array}$

Classification of TNM

\begin{tabular}{lrrrrrr} 
I & 101 & 46 & 42 & 13 & & \\
II & 130 & 53 & 54 & 23 & & \\
III & 124 & 47 & 56 & 21 & & \\
IV & 37 & 12 & 19 & 6 & & \\
Smoking b $^{\text {Yes }}$ & & & & & 1.396 & 0.498 \\
No & 168 & 64 & 79 & 25 & & \\
\hline
\end{tabular}

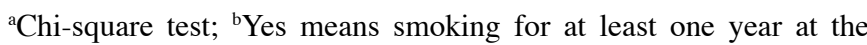
time of sample collection, otherwise no. AC, adenocarcinoma; SCC, squamous cell carcinoma; LAPTM4B, lysosome-associated protein transmembrane- $4 \beta$. Bold number indicates a statistically significant difference in this analysis.

and controls, while the age distribution revealed a significant difference $(\mathrm{P}<0.001)$.

The genotype and allele frequencies of $L A P T M 4 B$ in cases and controls in the present case-control study are summarized in Table II. We proved that the observed genotype frequencies for this polymorphism were in agreement with the HardyWeinberg equilibrium in the controls, suggesting that the control group could represent the whole population. Table II shows that there was a higher proportion of $L A P T M 4 B^{*} 1 / 2$ and $L A P T M 4 B^{*} 2 / 2$ in cases (43.6 and $16.1 \%$, respectively) than in controls (40.3 and $8 \%$, respectively). Odds ratio 
Table IV. Univariate Kaplan-Meier survival analysis of overall survival and disease-free survival in 97 patients with non-small cell lung cancer.

\begin{tabular}{|c|c|c|c|c|c|c|c|}
\hline \multirow[b]{2}{*}{ Prognostic variables } & \multirow{2}{*}{$\begin{array}{c}\text { No. of } \\
\text { cases }\end{array}$} & \multicolumn{3}{|c|}{ OS (months) } & \multicolumn{3}{|c|}{ DFS (months) } \\
\hline & & Mean \pm SE & $95 \% \mathrm{CI}$ & $\mathrm{P}^{\mathrm{a}}$ & Mean \pm SE & $95 \% \mathrm{CI}$ & $\mathrm{P}^{\mathrm{a}}$ \\
\hline Gender & & & & 0.727 & & & 0.954 \\
\hline Male & 59 & $35.2 \pm 3.1$ & $29.1-41.4$ & & $25.7 \pm 3.1$ & $19.6-31.8$ & \\
\hline Female & 38 & $35.1 \pm 3.7$ & $27.7-42.4$ & & $26.0 \pm 3.6$ & $19.0-33.0$ & \\
\hline Age (years) & & & & 0.963 & & & 0.933 \\
\hline$<60$ & 45 & $35.0 \pm 3.6$ & $27.8-42.1$ & & $25.1 \pm 3.4$ & $18.5-31.8$ & \\
\hline$\geq 60$ & 52 & $35.3 \pm 3.2$ & $29.1-41.6$ & & $26.3 \pm 3.2$ & $19.9-32.6$ & \\
\hline Pathological type & & & & 0.172 & & & 0.198 \\
\hline $\mathrm{AC}$ & 63 & $39.5 \pm 4.2$ & $31.2-47.8$ & & $23.8 \pm 2.8$ & $18.2-29.3$ & \\
\hline SCC & 34 & $32.8 \pm 2.9$ & $27.2-38.4$ & & $29.4 \pm 4.0$ & $21.5-37.2$ & \\
\hline Differentiation & & & & 0.016 & & & 0.056 \\
\hline Poorly & 42 & $27.3 \pm 3.2$ & $21.0-33.6$ & & $19.1 \pm 3.4$ & $12.4-25.8$ & \\
\hline Moderately & 24 & $35.7 \pm 5.2$ & $25.6-45.8$ & & $26.0 \pm 4.7$ & $16.9-35.2$ & \\
\hline Well & 31 & $44.5 \pm 3.8$ & $37.2-51.9$ & & $33.8 \pm 3.7$ & $26.7-41.0$ & \\
\hline Tumor size (cm) & & & & $<0.001$ & & & $<0.001$ \\
\hline$<4$ & 53 & $43.4 \pm 3.4$ & $36.7-50.0$ & & $34.9 \pm 3.4$ & $28.2-41.7$ & \\
\hline$\geq 4$ & 44 & $24.8 \pm 2.5$ & $19.8-29.7$ & & $15.1 \pm 2.3$ & $10.6-19.6$ & \\
\hline Lymph node metastasis & & & & $<0.001$ & & & $<0.001$ \\
\hline No & 51 & $47.4 \pm 3.1$ & $41.3-53.5$ & & $37.6 \pm 3.3$ & $31.3-44.0$ & \\
\hline Yes & 46 & $21.4 \pm 2.4$ & $16.6-26.2$ & & $12.9 \pm 2.3$ & $8.5 .4-17.4$ & \\
\hline Classification of TNM & & & & $<0.001$ & & & $<0.001$ \\
\hline I & 30 & $49.9 \pm 3.7$ & $42.7-57.1$ & & $40.3 \pm 3.9$ & $32.8-47.9$ & \\
\hline II & 35 & $35.3 \pm 3.7$ & $28.1-42.5$ & & $25.7 \pm 3.8$ & $18.3-33.0$ & \\
\hline III & 24 & $22.7 \pm 3.9$ & $15.1-30.2$ & & $14.7 \pm 3.6$ & 7.7-21.7 & \\
\hline IV & 8 & $12.3 \pm 2.5$ & 7.4-17.1 & & $4.0 \pm 1.6$ & $0.8-7.2$ & \\
\hline LAPTM4B genotypes & & & & 0.001 & & & 0.001 \\
\hline$* 1 / 1$ & 39 & $45.5 \pm 3.6$ & $38.6-52.5$ & & $35.2 \pm 3.7$ & $28.0-42.3$ & \\
\hline$* 1 / 2$ & 40 & $31.3 \pm 3.5$ & $24.4-38.1$ & & $22.5 \pm 3.5$ & $15.6-29.3$ & \\
\hline$* 2 / 2$ & 18 & $20.4 \pm 4.3$ & $12.1-28.8$ & & $12.8 \pm 4.1$ & 4.7-20.9 & \\
\hline
\end{tabular}

${ }^{a}$ Log-rank test. OS, overall survival; DFS, disease-free survival; CI, confidence interval; TNM, tumor-node-metastasis; LAPTM4B, lysosomeassociated protein transmembrane- $4 \beta$. Bold numbers indicate statistically significant differences in this analysis.

analysis indicated that $L A P T M 4 B^{*} 1 / 2, * 2 / 2$ were correlated with a significant increased risk of NSCLC compared with LAPTM4B*1/1 (OR, 1.48; 95\% CI, 1.076-2.037; OR, 2.855; $95 \% \mathrm{CI}, 1.722-4.734$, respectively). In addition, the frequency of $L A P T M 4 B^{*} 2$ was notably higher in cases than in controls (37.9 vs. $28.1 \%$, respectively). $L A P T M 4 B^{*} 2$ carriers had a 1.649-fold (95\% CI, 1.316-2.068) higher risk of developing NSCLC than non-LAPTM4B* 2 carriers. Our data indicated that $L A P T M 4 B^{*} 2$ was likely to be associated with an increased susceptibility to NSCLC in a Chinese population.

LAPTM4B polymorphism and clinicopathological variables. We investigated the distribution of clinical parameters such as gender, age, pathological type, differentiation degree, lymph node metastasis, smoking and tumor-node-metastasis (TNM) stage in different genotypes of LAPTM4B in these
392 patients. We found that $L A P T M 4 B^{*} 2$ was significantly associated with poor histopathologic differentiation $(\mathrm{P}=0.012)$, but not with gender, age, pathological type, lymph node metastasis, smoking and TNM stage $(\mathrm{P}>0.05)$, shown in Table III.

LAPTM4B genotype and NSCLC prognosis. We conducted survival analysis in these 97 followed-up patients to examine the impact of $L A P T M 4 B$ polymorphism on NSCLC prognosis. As of September 30, 2013 which was the end date for followup, $23(23.7 \%)$ patients were alive and 74 (76.3\%) patients had succumbed to the disease. We first performed univariate analysis of clinicopathological variables for prognosis using the Kaplan-Meier method and log-rank test. According to the survival analysis, the 5-year overall and disease-specific survival were 62.7 and $68.1 \%$, respectively. As shown in Table IV, it was of no statistically significant difference in 
Table V. Multivariate Cox regression model of overall survival and disease-free survival in 97 patients with non-small cell lung cancer.

\begin{tabular}{|c|c|c|c|c|c|c|}
\hline \multirow[b]{2}{*}{ Variables } & \multicolumn{3}{|c|}{ OS } & \multicolumn{3}{|c|}{ DFS } \\
\hline & $\mathrm{RR}$ & $95 \% \mathrm{CI}$ & $\mathrm{P}^{\mathrm{a}}$ & $\mathrm{RR}$ & $95 \% \mathrm{CI}$ & $\mathrm{P}^{\mathrm{a}}$ \\
\hline \multicolumn{7}{|c|}{ Tumor size $(\mathrm{cm})$} \\
\hline$\geq 4$ & 1.184 & $0.62-2.261$ & 0.61 & 1.393 & $0.75-2.587$ & 0.294 \\
\hline \multicolumn{7}{|c|}{ Lymph node metastasis } \\
\hline Yes & 2.261 & $1.241-4.116$ & 0.008 & 2.202 & $1.242-3.905$ & 0.007 \\
\hline \multicolumn{6}{|l|}{ Differentiation } & Well \\
\hline Moderately & 0.967 & $0.473-1.974$ & 0.926 & 0.952 & $0.498-1.821$ & 0.883 \\
\hline Poorly & 1.386 & $0.724-2.652$ & 0.325 & 1.273 & $0.702-2.31$ & 0.427 \\
\hline \multicolumn{7}{|c|}{ Classification of TNM } \\
\hline II & 1.527 & $0.783-2.981$ & 0.214 & 1.288 & $0.705-2.353$ & 0.411 \\
\hline III & 2.478 & $1.128-5.445$ & 0.024 & 2.102 & $1.031-4.285$ & 0.041 \\
\hline IV & 3.969 & $1.46-10.788$ & 0.007 & 4.502 & $1.705-11.89$ & 0.002 \\
\hline \multicolumn{7}{|c|}{ LAPTM4B genotypes } \\
\hline$* 1 / 2+* 2 / 2$ & 2.025 & $1.21-3.388$ & 0.007 & 1.678 & $1.044-2.696$ & $\mathbf{0 . 0 3 3}$ \\
\hline
\end{tabular}

${ }^{\mathrm{a} C}$ Cox regression test; RR, relative risk; CI, confidence interval; OS, overall survival; DFS, disease-free survival; TNM, tumor-node-metastasis; LAPTM4B, lysosome-associated protein transmembrane-4 $\beta$. Bold numbers indicate statistically significant differences in this analysis.
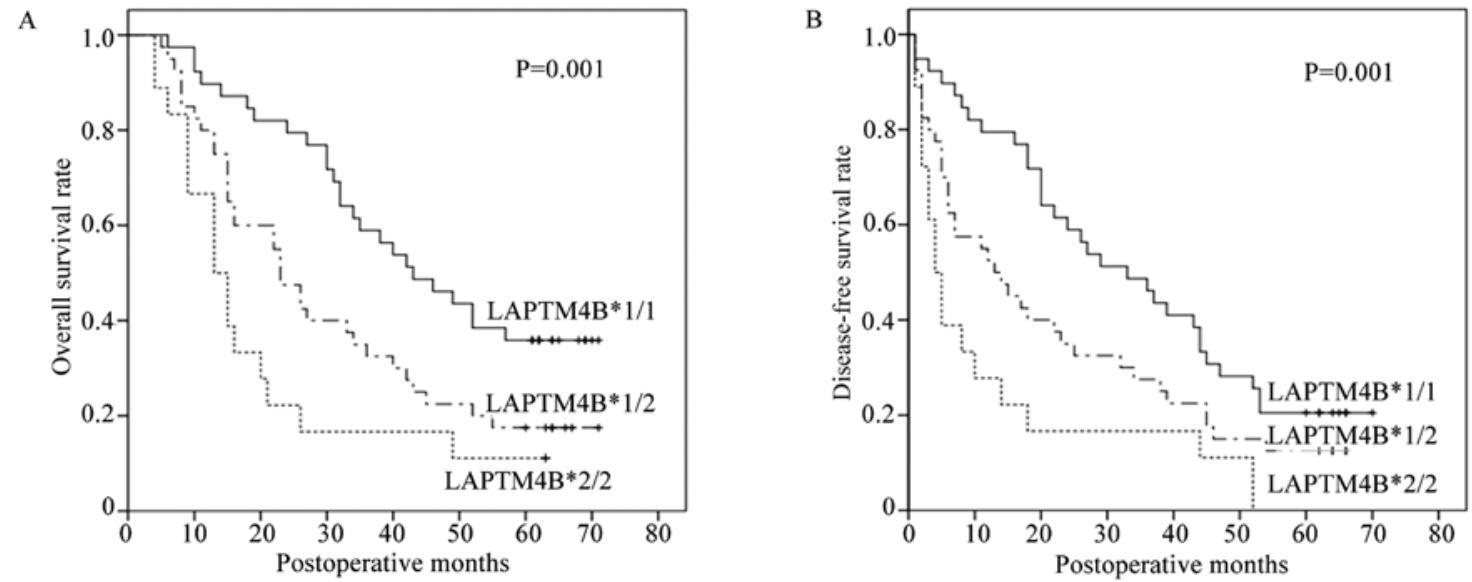

Figure 3. Kaplan-Meier curves of survival related to LAPTM4B polymorphisms in 97 non-small cell lung cancer patients. Patients with LAPTM4B*1/2 and LAPTM4B*2/2 had a poorer prognosis than patients with LAPTM4B*1/1. LAPTM4B, lysosome-associated protein transmembrane- $4 \beta$.

some clinical parameters, such as age, gender and pathological type $(\mathrm{P}>0.05)$. However, the overall 5-year survival rate of patients with $L A P T M 4 B^{*} 2 / 2$ and $L A P T M 4 B^{*} 1 / 2$ (11.1 and $17.5 \%$, respectively, vs. $35.9 \%, \mathrm{P}=0.001$ ) was significantly lower than that of $L A P T M 4 B^{*} 1 / 1$ carriers. In addition, KaplanMeier analysis of disease-free survival also demonstrated poor 5-year survival rate in patients with LAPTM4B*2/2 and $L A P T M 4 B^{*} 1 / 2$ (0 and $12.5 \%$, respectively, vs. $20.5 \%$, $\mathrm{P}=0.001)$ shown in Fig. 3. Furthermore, poor prognosis was strikingly associated with large tumor size $(\mathrm{P}<0.01$ and $\mathrm{P}<0.01$, respectively), high grade of histopathological differentiation $(\mathrm{P}=0.016$ and $\mathrm{P}=0.056$, respectively), positive lymph node metastasis $(\mathrm{P}<0.01$ and $\mathrm{P}<0.01$, respectively) and high TNM stage $(\mathrm{P}<0.01$ and $\mathrm{P}<0.01$, respectively).

LAPTM4B genotype is an independent prognostic marker for NSCLC patients. To analyze the independent factor of $L A P T M 4 B$ polymorphism on prognosis, a multivariate Cox 
regression model adjusted for statistically significant prognostic factors was performed. Table $\mathrm{V}$ shows that subjects with the $L A P T M 4 B^{*} 2$ allele had, respectively, 2.025-fold (95\% CI, 1.21-3.388; $\mathrm{P}=0.007)$ increased mortality and 1.678fold (95\% CI, 1.044-2.696; $\mathrm{P}=0.033)$ increased recurrence of NSCLC than those carrying LAPTM $4 B^{*} 1 / 1$ genotype, demonstrating that the $L A P T M 4 B$ genotype was an independent prognostic factor for NSCLC patients. In addition, lymph node metastasis and TNM classification also retained their prognostic significance.

\section{Discussion}

In the present study, we detected the polymorphism of $L A P T M 4 B$ genotypes in NSCLC patients, then analyzed the relationship between distribution of $L A P T M 4 B$ genotypes and susceptibility, prognosis of lung cancer. Our finding was that patients with $L A P T M 4 B^{*} 2$ showed a higher risk of susceptibility and mortality of NSCLC compared with non-carriers. To our knowledge, this is the first study to prove polymorphism of $L A P T M 4 B$ may act as an indicator for the prognosis of NSCLC. Our results are consistent with the putative role $L A P T M 4 B$ plays in carcinogenesis and tumor progression.

$L A P T M 4 B$, a novel oncogene, was first detected in hepatocellular carcinoma and was then found upregulated in various solid malignant tumors (24). LAPTM4B is closely related with the biological behaviors of malignant tumors. An increase in LAPTM $4 B$ expression, as measured by mRNA and protein, was associated with tumor progression and poorer survival in patients with breast (25), pancreatic (8), colon (26), ovary (27) and cervical cancer (11). Furthermore, extensive studies have been performed to account for such outcomes. Studies have shown that upregulation of LAPTM4B could promote cell proliferation (28), invasion, migration (29) and may inhibit cell apoptosis $(30,31)$ in vitro, while in nude mice the time of tumorigenesis was markedly shortened (29). It was assumed that various signal molecules were associated with cellular malignant transformation after the alteration of $L A P T M 4 B$ protein expression level. It has been confirmed that $L A P T M 4 B$ protein could upregulate some proliferation-promoting transcription factors such as c-Myc, c-Jun and c-Fos, and cell cycle-promoting proteins such as cyclin D1 and E (28). Meanwhile, it could also activate PI3K/AKT signaling pathway to motivate cellular multidrug resistance (31). A recent study clarified that cAMP responsive element binding protein-1 (CREB1) played an important role in $L A P T M 4 B$ transcriptional regulation (32).

The unique region of 19-bp sequence at 5'UTR in the first exon was identified as the difference between $L A P T M 4 B^{*} 1$ and $L A P T M 4 B * 2$. The 19-bp difference in the first exon of the $L A P T M 4 B$ gene altered the open reading frame (ORF), so it may influence the structure and function of the protein encoded by it. Previous studies have shown that LAPTM4B*2 allele played important roles in the susceptibility and prognosis of many tumors. To date, the exact mechanism of the phenomenon has not yet been revealed. It has been reported that a $40 \mathrm{kD}$ protein was encoded by $L A P T M 4 B^{*} 2$ allele with an extra 53 amino acids compared with the $L A P T M 4 B^{*} 1$ allele encoding a $35 \mathrm{kD}$ protein, which may explain such a difference. Different structures and activities of proteins could alter the cellular metabolism and signal pathway, then induce the malignant transformation. This area requires further study.

The present study was carried out under the strict rules of clinical trial, hence our conclusions are firm. Our data demonstrated that $L A P T M 4 B^{*} 2$ is associated with NSCLC susceptibility. This is also the first study to clarify that the polymorphism of $L A P T M 4 B$ genotype is related to NSCLC progression and prognosis. Although the exact molecular mechanisms which underlie the function of $L A P T M 4 B$ in lung carcinogenesis have yet to be fully clarified, $L A P T M 4 B^{*} 2$ could be a novel potential marker to estimate susceptibility and prognosis of NSCLC.

\section{Acknowledgements}

This study was supported by the National Natural Science Foundation of China (no. 30571844), the Science and Technology Development Foundation of Shandong Province (no. 2009GG10002007), and the National Natural Science Foundation of Shandong Province (no. ZR2009CM090). The authors thank all the people and patients who participated in the present study.

\section{References}

1. Jemal A, Bray F, Center MM, Ferlay J, Ward E and Forman D: Global cancer statistics. CA Cancer J Clin 61: 69-90, 2011.

2. Brognard J, Clark AS, Ni Y and Dennis PA: Akt/protein kinase B is constitutively active in non-small cell lung cancer cells and promotes cellular survival and resistance to chemotherapy and radiation. Cancer Res 61: 3986-3997, 2001.

3. Couraud S, Zalcman G, Milleron B, Morin F and Souquet PJ: Lung cancer in never smokers - a review. Eur J Cancer 48: 1299-1311, 2012.

4. Sun S, Schiller JH and Gazdar AF: Lung cancer in never smokers - a different disease. Nat Rev Cancer 7: 778-790, 2007.

5. Toh CK, Gao F, Lim WT, et al: Never-smokers with lung cancer: epidemiologic evidence of a distinct disease entity. J Clin Oncol 24: 2245-2251, 2006.

6. Liu X, Zhou R, Zhang Q, et al: Identification and characterization of LAPTM4B encoded by a human hepatocellular carcinomaassociated novel gene. Beijing Da Xue Xue Bao 35: 340-347, 2003 (In Chinese)

7. Shao GZ, Zhou RL, Zhang QY, et al: Molecular cloning and characterization of $L A P T M 4 B$, a novel gene upregulated in hepatocellular carcinoma. Oncogene 22: 5060-5069, 2003.

8. Zhang G, Liang Y, Huang Y, Chen Y and Zhou R: Elevated lysosome-associated protein transmembrane- $4 \beta-35$ is an independent prognostic marker in pancreatic carcinoma. J Int Med Res 40: 1275-1283, 2012.

9. Zhou L, He XD, Chen J, et al: Overexpression of LAPTM4B-35 closely correlated with clinicopathological features and postresectional survival of gallbladder carcinoma. Eur J Cancer 43: 809-815, 2007.

10. Yang Y, Yang H, McNutt MA, et al: LAPTM4B overexpression is an independent prognostic marker in ovarian carcinoma. Oncol Rep 20: 1077-1083, 2008.

11. Meng F, Luo C, Hu Y, et al: Overexpression of LAPTM4B-35 in cervical carcinoma: a clinicopathologic study. Int J Gynecol Pathol 29: 587-593, 2011.

12. Wang S, Zhang QY and Zhou RL: Relationship between LAPTM $4 B$ gene polymorphism and susceptibility of primary liver cancer. Ann Oncol 23: 1864-1869, 2012.

13. Liu Y, Zhang QY, Qian N and Zhou RL: Relationship between $L A P T M 4 B$ gene polymorphism and susceptibility of gastric cancer. Ann Oncol 18: 311-316, 2007.

14. Cheng XJ, Xu W, Zhang QY and Zhou RL: Relationship between $L A P T M 4 B$ gene polymorphism and susceptibility of colorectal and esophageal cancers. Ann Oncol 19: 527-532, 2008.

15. Yang H, Zhai G, Ji X, Xiong F, Su J and McNutt MA: Correlation of LAPTM4B polymorphisms with gallbladder carcinoma susceptibility in Chinese patients. Med Oncol 29: 2809-2813, 2012. 
16. Xu Y, Liu Y, Zhou R, et al: LAPTM4B polymorphisms is associated with ovarian cancer susceptibility and its prognosis. Jpn J Clin Oncol 42: 413-419, 2012.

17. Li X, Kong X, Chen X, et al: LAPTM4B allele $* 2$ is associated with breast cancer susceptibility and prognosis. PLoS One 7: e44916, 2012.

18. Deng LJ, Zhang QY, Liu B and Zhou RL: Relationship between $L A P T M 4 B$ gene polymorphism and susceptibility of lung cancer. Beijing Da Xue Xue Bao 37: 302-305, 2005 (In Chinese).

19. Li C, Zhou Q, Wang Y, Chen X, Yang X and Zhu D: Relationship between LAPTM4B gene polymorphism and susceptibility of lung cancer. Zhongguo Fei Ai Za Zhi 9: 109-112, 2006 (In Chinese)

20. Zhai G, Yan K, Ji X, et al: LAPTM4B allele *2 is a marker of poor prognosis for gallbladder carcinoma. PLoS One 7: e45290, 2012.

21. Yang H, Zhai G, Ji X, Xiong F, Su J and McNutt MA: LAPTM4B allele $* 2$ is a marker of poor prognosis following hepatic tumor resection for hepatocellular carcinoma. PLoS One 7: e34984, 2012.

22. Meng F, Li H, Zhou R, Luo C, Hu Y and Lou G: LAPTM4B gene polymorphism and endometrial carcinoma risk and prognosis. Biomarkers 18: 136-143, 2013.

23. Sobin L GM and Wittekind C (eds): TNM Classification of Malignant Tumours. 7th edition. Wiley-Blackwell, New York, 2010.

24. Kasper G, Vogel A, Klaman I, et al: The human LAPTM4b transcript is upregulated in various types of solid tumours and seems to play a dual functional role during tumour progression. Cancer Lett 224: 93-103, 2005.
25. Xiao M, Jia S, Wang H, Wang J,Huang Y and Li Z: Overexpression of $L A P T M 4 B$ : an independent prognostic marker in breast cancer. J Cancer Res Clin Oncol 139: 661-667, 2013.

26. Kang Y, Yin M, Jiang W, et al: Overexpression of LAPTM4B-35 is associated with poor prognosis in colorectal carcinoma. Am J Surg 204: 677-683, 2012.

27. Yin M, Lou C, Zhang W, et al: LAPTM4B overexpression is a novel independent prognostic marker for metastatic ovarian tumors. Int J Gynecol Cancer 22: 54-62, 2012.

28. Liu X, Xiong F, Wei X, Yang H and Zhou R: LAPTM4B-35, a novel tetratransmembrane protein and its PPRP motif play critical roles in proliferation and metastatic potential of hepatocellular carcinoma cells. Cancer Sci 100: 2335-2340, 2009.

29. Yang H, Xiong F, Wei X, Yang Y, McNutt MA and Zhou R: Overexpression of LAPTM4B-35 promotes growth and metastasis of hepatocellular carcinoma in vitro and in vivo. Cancer Lett 294: 236-244, 2010.

30. Zhou L, He XD, Yu JC, Zhou RL, Shan Y and Rui JA: Overexpression of LAPTM4B-35 attenuates epirubucin-induced apoptosis of gallbladder carcinoma GBC-SD cells. Surgery 150: 25-31, 2011.

31. Li L, Wei XH, Pan YP, et al: LAPTM4B: a novel cancerassociated gene motivates multidrug resistance through efflux and activating PI3K/AKT signaling. Oncogene 29: 5785-5795, 2010.

32. Zhang $\mathrm{M}, \mathrm{Xu} J \mathrm{JJ}$, Zhou RL and Zhang QY: cAMP responsive element binding protein-1 is a transcription factor of lysosomalassociated protein transmembrane-4 beta in human breast cancer cells. PLoS One 8: e57520, 2013. 